\title{
Measurement of ultrafine aerosol size distributions by a combination of diffusion screen separators and condensation particle counters
}

\author{
Philipp Feldpausch ${ }^{1}$, Markus Fiebig, Lutz Fritzsche ${ }^{2}$, Andreas Petzold* \\ Deutsches Zentrum für Luft- und Raumfahrt Oberpfaffenhofen, Institut für Physik der Atmosphäre, 82234 Wessling, Germany
}

Received 1 February 2005; received in revised form 20 April 2005; accepted 21 April 2005

\begin{abstract}
The quasi-real-time measurement of ultrafine aerosol size distributions by a combination of a diffusion screen separator (DS), which is similar to a single stage of a screen-type diffusion battery, and a condensation particle counter (CPC) was developed, characterised, and evaluated. The instrument reports information on the particle size distribution for particle diameters between approximately 20 and $100 \mathrm{~nm}$. The instrument system was characterised for various operation conditions in order to provide reliable instrument transfer functions for data inversion purposes. The penetration behaviour of specified diffusion screens was examined for the expected range of operation pressure conditions $(200 \mathrm{hPa} \leqslant p \leqslant 955 \mathrm{hPa})$, number of diffusion screens $\left(3 \leqslant n_{\mathrm{S}} \leqslant 17\right)$, and volumetric flow rates $(0.99 \leqslant q \leqslant 1.89 \mathrm{Lpm})$. The comparison of results between the calibration experiments and the "classical" filtration theory of particle deposition on fibres or wires shows excellent agreement for the entire range of investigated operation conditions. The calibration results were evaluated in a validation experiment using monodisperse test aerosol particles. In a final study, the entire measurement system consisting of three parallel-operated CPC-DS combinations was successfully applied to polydisperse laboratory-generated test aerosols. A comparison of size distributions obtained from a differential mobility analyser (DMA) and the presented instrument shows very close agreement for cases with the modal diameter of the investigated aerosol size distribution being in the sub-100 $\mathrm{nm}$ range.
\end{abstract}

(C) 2005 Elsevier Ltd. All rights reserved.

Keywords: Nanoparticles; Size distribution measurement; Diffusion battery; Diffusion screen; Real-time particle measurement

\footnotetext{
* Corresponding author. Tel.: +498153 28 2592; fax: +498153281841.

E-mail address: andreas.petzold@dlr.de (A. Petzold).

${ }^{1}$ Present address: Ludwig-Maximilians-Universität München, Lehrstuhl Physikalische Chemie, Butenandtstrasse 5-13, 81377 München, Germany.

${ }^{2}$ Present address: Bundesanstalt für Materialforschung und- prüfung, II.2901, Unter den Eichen 87, 12205 Berlin, Germany.
} 


\section{Introduction}

Airborne atmospheric aerosol particles influence human life in many different ways. In urban environments, inhaled aerosol particles can cause adverse health effects, while in the troposphere and particularly downwind of major pollution sources, aerosol particles may influence the radiation balance of Earth's atmosphere. Understanding these effects requires detailed information on how aerosol particles either enter the atmosphere or form in the atmosphere, and how they are transformed before being removed by dry or wet deposition. Among the key processes in this context, there are the formation of new atmospheric particles by gas-to-particle conversion or nucleation, respectively, and their subsequent growth to larger sizes (Kulmala et al., 2004 and references given there).

Since the sizes of atmospheric aerosol particles usually extent over several decades of diameters, different techniques have to be applied for measuring a complete aerosol size distribution from nucleation mode size $\left(D_{\mathrm{p}}=3-10 \mathrm{~nm}\right)$, to the Aitken mode range $\left(D_{\mathrm{p}}=10-100 \mathrm{~nm}\right)$, and finally to the accumulation mode range $\left(D_{\mathrm{p}}=100-1000 \mathrm{~nm}\right)$. While larger particles in the accumulation mode $\left(D_{\mathrm{p}}>100 \mathrm{~nm}\right) \mathrm{can}$ be measured directly by light scattering techniques, nanoparticles in the sub-100 $\mathrm{nm}$ size range require different techniques. Particles of size 3-20 nm can be counted by condensation particle counters (CPC). In this type of instrument, small particles grow by condensation in a supersaturated environment until they rich a size which is accessible by optical methods (Hinds, 1999). During the growth process, information on the initial size of the droplet nuclei is lost. One possible solution for the measurement of particle size distributions by means of CPC methods is described by Schröder and Ström (1997), Brock et al. (2000) and by Schröder (2000) and Stein, Schröder, and Petzold (2001).The developments described by Schröder (2000) and Stein et al. (2001) resulted in the condensation particle size analyser (CPSA). The CPSA consists of four CPC with adjustable diameters of $50 \%$ response efficiency $D_{\mathrm{p} 50}$ which can be set to values between 3 and $20 \mathrm{~nm}$. The CPC are operated in parallel, so that real-time size information on nucleation mode particles is accessible. All proposed methods are based on the Kelvin effect which governs the growth of a droplet on an insoluble nucleus in a supersaturated environment. The minimum size of a particle which is required for the activation of droplet growth on the nucleus is inversely proportional to the natural logarithm of the supersaturation of the condensable species (Hinds, 1999). Thus, operating several CPC in parallel which are set to different minimum detectable diameters permits the measurement of particle size distributions in the sub- $20 \mathrm{~nm}$ size range.

Particles larger than $10 \mathrm{~nm}$ in diameter are usually sized with the well-known and widely applied differential mobility analyser (DMA) technique (Flagan, 2001). The DMA permits a precise determination of particle sizes by electrical means, i.e., the method requires charged particles. Furthermore, even in the so-called scanning mode (Flagan, 2001), the method delivers no real-time data. The minimum time resolution is of the order of $1-5 \mathrm{~min}$, depending on the particle concentration. In a recent study, Bukowiecki et al. (2002) demonstrated a real-time characterisation of ultrafine and accumulation mode particles in combustion aerosols by using diffusion charger methods, the photoelectric aerosol sensor and a CPC.

Another well-established method for sizing ultrafine or nanoparticles is the application of a diffusion battery, see Knutson (1999) for a review of this technique. In the common combination with CPC as particle detecting units, a diffusion battery permits no real-time data analysis, but Fierz, Scherrer, and Burtscher (2002) presented an electrical diffusion battery which measures real-time size distributions of charged particles. However, for applications which are sensitive to time resolution, there is still a need for an instrument which permits real-time sizing of sub-100 nm particles independent of electrical charge. 
The presented combination of diffusion screen separators (DS) and CPC aims at filling this serious gap in aerosol instrumentation.

\section{Theory of deposition}

As is reported by Brock et al. (2000), Schröder (2000) and Stein et al. (2001), particle sizing by a set of parallel-operated CPC which are set to various supersaturations of the working fluid is only possible up to particle diameters of approximately $20 \mathrm{~nm}$ for the most commonly used CPC working fluid $n$-butyl alcohol. The minimum cut-off diameter at $50 \%$ detection efficiency $D_{\mathrm{p} 50}$ can be shifted to larger particle sizes either by using different working fluids (Brock et al., 2000) or by connecting the CPC to a diffusion screen separator. The latter method is described and evaluated in this work.

The DS consists simply of a set of fine metallic meshes which are placed in the sample flow upstream the CPC. Particles are removed from the aerosol by deposition on the wires of the meshes. The deposition efficiency, or its counterpart penetration $P$, respectively, depends on particle size. The theory of particle transfer through a fibrous medium like a mesh or a fibrous filter is linked to the theory of particle deposition on a filter fibre. The penetration $P$ of a fibrous filter denotes the fraction of particles of a given size which penetrate through the fibrous medium. In turn, the deposited fraction is $1-P$. The penetration $P$ is expressed as (Cheng \& Yeh, 1980)

$$
P=\exp \left(-\frac{4 \alpha E_{\Sigma} t}{\pi(1-\alpha) D_{\mathrm{f}}}\right),
$$

where $\alpha$ is the solidity volume fraction of the filter material, $E_{\Sigma}$ is the total single-fibre efficiency concerning particle removal, $t$ is the entire thickness of the filter or mesh, and $D_{\mathrm{f}}$ is the single-fibre diameter. Particles are deposited on a fibre by interception $\left(E_{\mathrm{R}}\right)$, impaction $\left(E_{\mathrm{I}}\right)$, diffusion $\left(E_{\mathrm{D}}\right)$, gravitational sedimentation $\left(E_{\mathrm{G}}\right)$, and electrostatic attraction $\left(E_{\mathrm{q}}\right)$; for details and illustrative graphical presentations, see Hinds (1999). These mechanisms are taken into account by the total single-fibre efficiency $E_{\Sigma}$. Assuming the independence of the deposition processes, the total single-fibre efficiency $E_{\Sigma}$ corresponds to a good approximation to

$$
E_{\Sigma} \cong E_{\mathrm{R}}+E_{\mathrm{I}}+E_{\mathrm{D}}+E_{\mathrm{DR}}+E_{\mathrm{G}}+E_{\mathrm{q}} .
$$

The term $E_{\mathrm{DR}}$ accounts for enhanced deposition due to interception of diffusing particles. The equations governing the single deposition processes are given in Hinds (1999). They are valid for standard conditions $(p=1013 \mathrm{hPa}, 293 \mathrm{~K})$.

The single-fibre efficiency for particle deposition by interception, $E_{\mathrm{R}}$, is

$$
\begin{aligned}
& E_{\mathrm{R}}=\frac{(1-\alpha) R^{2}}{K u(1+R)}, \\
& K u=-\frac{\ln (\alpha)}{2}-\frac{3}{4}+\alpha-\frac{\alpha^{2}}{4}, \\
& R=\frac{D_{\mathrm{p}}}{D_{\mathrm{f}}} .
\end{aligned}
$$


$R$ denotes the ratio of diameters of the particle and the intercepting object, $K u$ is the Kuwabara factor. The single-fibre efficiency for impaction, $E_{\mathrm{I}}$, is characterised by the Stokes number $S t k$.

$$
\begin{aligned}
& E_{\mathrm{I}}=\frac{S t k J(\alpha, R)}{2 K u^{2}}, \\
& S t k=\frac{\tau U_{0}}{D_{\mathrm{f}}}=\frac{\rho_{\mathrm{p}} D_{\mathrm{p}}^{2} C_{\mathrm{c}} U_{0}}{18 \eta_{\mathrm{g}} D_{\mathrm{f}}}, \\
& J=\left(29.6-28 \alpha^{0.62}\right) R^{2}-27.5 R^{2.8} \text { for } R<0.4 .
\end{aligned}
$$

$U_{0}$ is the undisturbed flow velocity and $\rho_{\mathrm{p}}$ the mass density of the particles. $C_{\mathrm{c}}$ is the Cunningham factor, and $J$ is an empirical function of parameters $R$ and $\alpha$.

The most important mechanism for particles with $D_{p}<100 \mathrm{~nm}$, or particles of the sub-100 nm fraction, respectively, is the deposition by diffusion. The single-fibre efficiency $E_{\mathrm{D}}$ for diffusion deposition of particles on a fibre of diameter $D_{\mathrm{f}}$ is characterised by the diffusional Peclet number $P e$

$$
\begin{aligned}
& E_{\mathrm{D}}=B P e^{-2 / 3}, \\
& P e=\frac{D_{\mathrm{f}} U_{0}}{D}, \\
& D=\frac{k T C_{\mathrm{c}}\left(D_{\mathrm{p}}\right)}{3 \pi \eta_{\mathrm{g}} D_{\mathrm{p}}} .
\end{aligned}
$$

$B$ is an empirical factor which is reported by Kirsch and Fuchs (1968) as a constant value of 2.7 for so-called fan model filters. A fan model filter consists of a system of parallel equidistant layers of circular cylinders which is exposed to a laminar flowing gas. In a single layer the cylinders are parallel and equidistant, but in different layers they are randomly oriented. The value 2.7 was approved by Cheng and Yeh (1980). They used for their investigations screens similar to those applied in this study. Therefore as a first approximation, we assumed $B=2.7$ for all investigated operation conditions. Possible dependencies of $B$ on the investigated operation parameters are discussed in a separate subsection.

Since the probability of deposition by gravitational sedimentation is very small for sub-100 nm particles, this deposition mechanism was neglected. Furthermore, in all conducted experiments the particles were brought into a Boltzmann charge equilibrium before they entered the DS, and the used screens were electrically grounded. So, the predominant fraction of the small particles of interest $\left(D_{\mathrm{p}} \leqslant 50 \mathrm{~nm}\right)$ were electrically neutral. Thus, deposition by electrostatic forces, $E_{\mathrm{q}}$, was neglected. The negligibility of the terms $E_{\mathrm{G}}$ and $E_{\mathrm{q}}$ was also justified experimentally.

For illustration, Fig. 1 shows the penetration curves according to the considered particle deposition processes along with the resulting total penetration curve. The variation of $P$ with particle size $D_{\mathrm{p}}$ is the theoretical basis for the size-dependent removal of particles from an aerosol by a DS. Following Eq. (1), the penetration $P$ depends significantly on the total mesh thickness $t$ which is equal to $n_{\mathrm{S}}$ (number of screens) times $t_{\mathrm{S}}$ (single screen thickness). Via the mechanism of inertial impaction, the penetration $P$ depends also on the volumetric flow rate $q$ which determines the flow velocity $U_{0}$. Finally, the pressure dependence of $P$ is introduced by the Cunningham factor $C_{\mathrm{c}}$, because a change in pressure affects the 


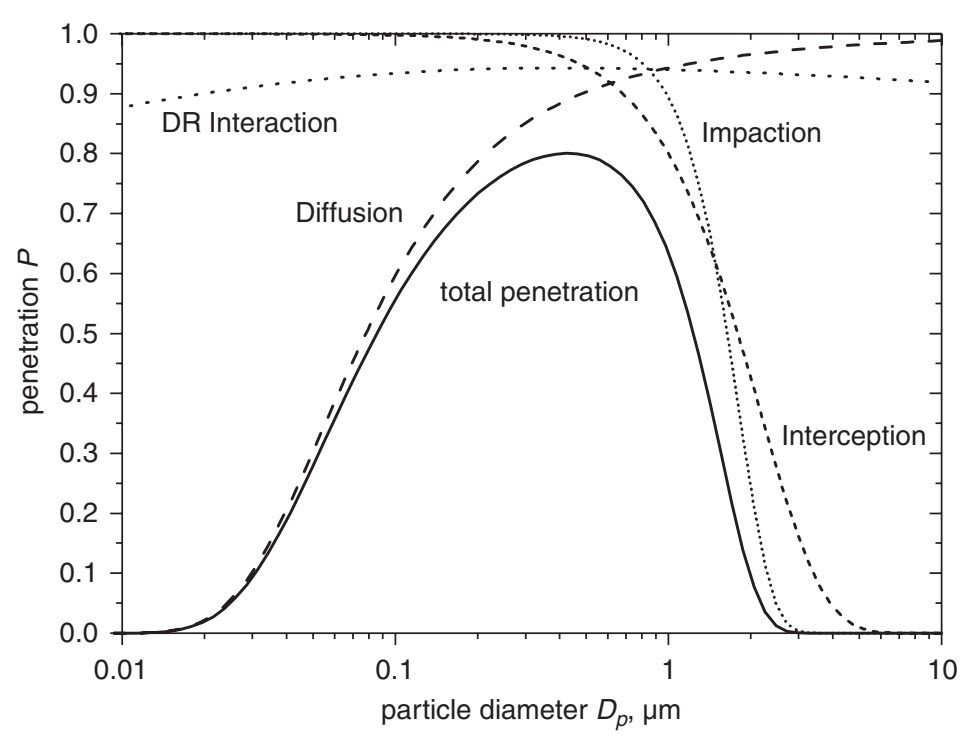

Fig. 1. Penetration of a diffusion separator: penetration caused by single-fibre efficiencies and total penetration.

mean free path $\lambda_{\mathrm{p}}$ and thus $C_{\mathrm{c}}$. Due to the potential application conditions for CPC-DS combinations, the variation of penetration $P$ by the variation of one of these three parameters was experimentally investigated within the ranges $3 \leqslant n_{\mathrm{S}} \leqslant 17,0.99 \leqslant q \leqslant 1.89 \mathrm{Lpm}$, and $200 \leqslant p \leqslant 955 \mathrm{hPa}$.

\section{Instrument description}

Fig. 2 shows a sectional view of the schematic set-up of the developed DS. All metal parts are manufactured of stainless steel. The applied DS is comparable to the commercially distributed Particle Size Selector Model 376060 of TSI Inc. The aerosol expands in the entrance cone. Then it passes the screens and particles are deposited on the screen wires by the described mechanisms. The effective cross-sectional area of the undisturbed aerosol flow through the DS is defined by the inside diameter of the disk (41 $\mathrm{mm})$ which fixes the screens. The disk itself is fixed by a spring in the bushing. Before the aerosol exits the DS, it is compressed in the exit cone. Both cones including the O-ring seals and the cap nut form a pressure and gas tight body. This body is a commercially distributed in-line filter holder from PALL Corporation (PALL Prod. No. 2220). It was slightly modified to hold the screen bushing. The distance between the inlet and the first screen is $20 \mathrm{~mm}$ which is sufficient to allow for the development of laminar flow conditions, so that the application of the fan model is justified. The overall length of the DS housing is only $45 \mathrm{~mm}$, so that for a volumetric flow of $1 \mathrm{Lpm}$ particle losses at the housing walls are $\leqslant 2 \%$ for the considered particle size range of $D_{\mathrm{p}} \geqslant 10 \mathrm{~nm}$ (Hinds, 1999) and can thus be neglected. The screens are commercially distributed by Spörl KG (Staudenweg 13, 72517 Sigmaringendorf, Germany). Technical specifications of the screens as reported by the manufacturer are: fibre diameter $D_{\mathrm{f}}=20 \mu \mathrm{m}$, aperture size $w=20 \mu \mathrm{m}$, material: 1.4401/AISI 316 stainless steel, wire density $\rho=7.85 \mathrm{~kg} / \mathrm{dm}^{3}$. The solidity volume fraction $\alpha$ 


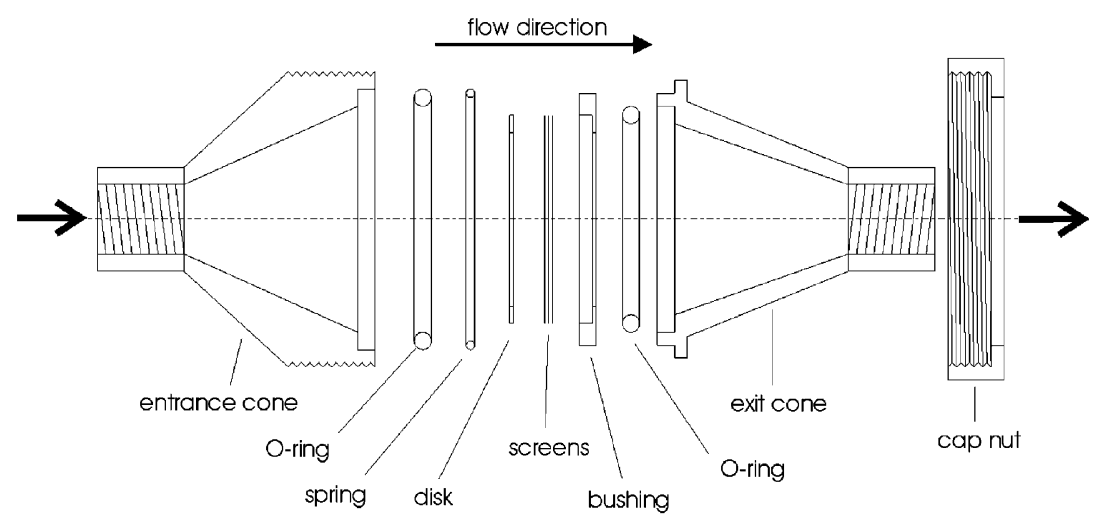

Fig. 2. Schematic of the diffusion screen separator (DS).

was estimated by measuring the volume of solid and total volume of a screen,

$$
\alpha=\frac{\text { fibre volume }}{\text { total volume }}=\frac{4 m_{\mathrm{S}}}{\pi D_{\mathrm{S}}^{2} t_{\mathrm{S}} \rho} .
$$

From direct measurements the average mass $m_{\mathrm{S}}$, the entire thickness $t_{\mathrm{S}}$, and the outer diameter $D_{\mathrm{S}}$ of a screen are $0.20 \pm 0.01 \mathrm{~g}, 42 \pm 1 \mu \mathrm{m}$, and $45.5 \pm 0.5 \mathrm{~mm}$, respectively. Hence, using Eq. (6), solidity $\alpha=0.368 \pm 0.021$.

\section{Calibration experiments}

\subsection{Experimental set-up}

The penetration of a given DS was characterised by using monodisperse carbonaceous aerosol particles. The aerosol was generated by an aerosol generator GfG 1000 (PALAS, Karlsruhe, Germany), which is described by Helsper, Mölter, Löffler, Wadenpohl, and Kaufmann (1993), and size-selected by a DMA (TSI, Model 3071A) which was operated in the overpressure mode. The aerosol exiting the DMA is not strictly monodisperse but may contain multiply charged particles which are of the same electrical mobility but of larger size than the singly charged particles. However, the calibration studies were focussing on particles smaller than $300 \mathrm{~nm}$ in diameter. From the Boltzmann charge distribution (Hinds, 1999) it is known that only $10 \%$ of particles of size $D=200 \mathrm{~nm}$ carry two unit charges and $<3 \%$ carry 3 or more unit charges. For $100 \mathrm{~nm}$ particles the corresponding fraction of multiple-charged particles is $<5 \%$. Since the aerosol was generated by the PALAS GFG 1000 generator which produces predominantly particles smaller than $300 \mathrm{~nm}$ in diameter, the effect of multiple-charged particles can be neglected in the considered size range. For the presented application, the DMA can be used as a reliable source for quasi-monodisperse aerosols. The carbonaceous aerosol was suspended in a mixture of the inert carrier gas Argon and particlefree pressurised dilution air. Carbonaceous aerosol particles were used for the calibration experiments, because they are similar to combustion particles with respect to their morphology, and as a first application for the presented instrument, the measurement of combustion particles was planned. 


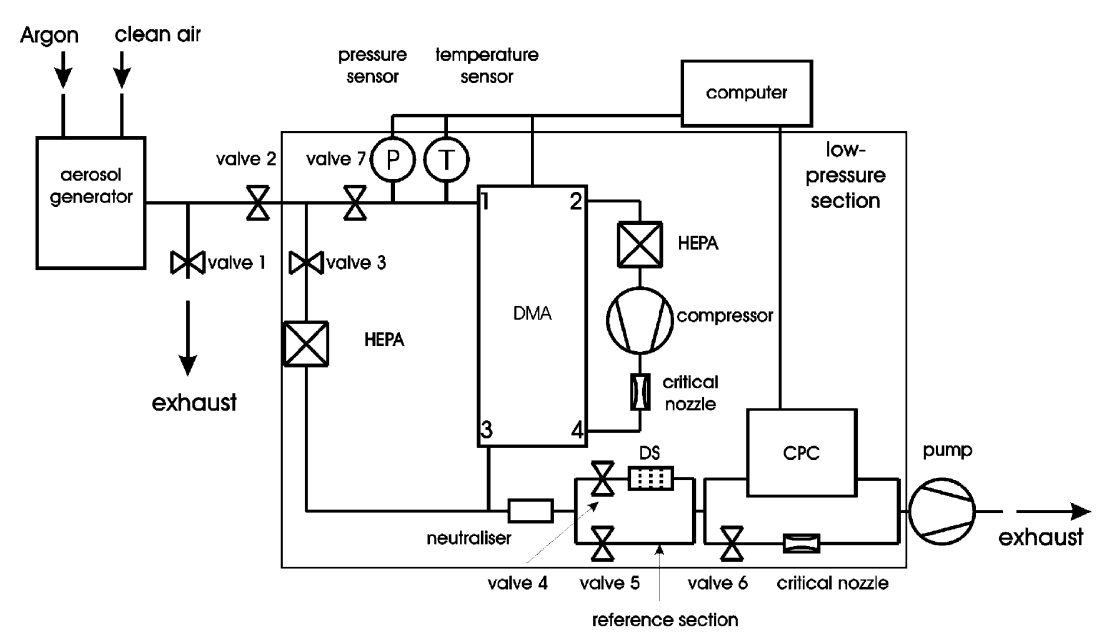

Fig. 3. Schematic set-up of the calibration experiment.

In order to obtain penetration values for the selected particle sizes, the particle number density of the particles entering $\left(N_{\text {in }}\right)$ and exiting $\left(N_{\text {out }}\right)$ the DS under investigation had to be measured. The ratio $N_{\text {out }} / N_{\text {in }}$ then equals $P$. Fig. 3 shows schematically the experimental set-up for the calibration studies. The polydisperse probe aerosol was fed into the DMA section via a T-piece. Valve 2 in Fig. 3 was used to control the pressure in the low-pressure section of the set-up. The DMA was operated in a closed-loop set-up (Jokinen \& Mäkelä, 1997) for maintaining constant flow conditions at various pressure levels in the low-pressure section. Particle sizes were selected between 10 and $500 \mathrm{~nm}$. For maintaining a constant sheath to mono flow ratio of 1:10 in the DMA even during the experiments when the flow through the DS was varied, a particle-free air flow controlled by valve 3 and cleaned by a HEPA (high-efficiency particle absorber) filter was mixed with the monodisperse aerosol flow downstream the DMA. Since all particles exiting the DMA are charged, the monodisperse aerosol was brought into charge equilibrium by using a second neutraliser downstream the DMA. This aerosol neutralisation step was necessary for avoiding particle deposition by electrostatic attraction. The neutralised monodisperse aerosol was then sucked either through the DS or through a reference section consisting of a clean pipe of similar length. To obtain a penetration value $P\left(n_{\mathrm{S}}, q, p, d_{\mathrm{p}}\right)$ at a defined operation status, the valves 4 and 5 were alternately opened and closed. The number densities of particles entering ( $N_{\text {in }}$ : valve 4 closed, valve 5 open) and exiting ( $N_{\text {out }}$ : valve 4 open, valve 5 closed) the DS were detected by a CPC (TSI Model 3010). The total aerosol volume flow rate $q$ in the DS-CPC section was kept at a fixed value by critical orifices in the CPC itself and in the CPC bypass branch. Table 1 summarises the range of investigated parameter configurations.

\subsection{Results and discussion}

In this section, the experimental penetration values $P^{\mathrm{ex}}$ are compared with the values $P^{\text {th }}$ calculated from the above-outlined theory (Hinds, 1999). Eqs. (1)-(5) and $B=2.7$ were used for the calculation of $P^{\text {th }}$. Furthermore, the mass density of the used carbonaceous particles was set to $1.25 \times 10^{3} \mathrm{~kg} \mathrm{~m}^{-3}$ for determining $E_{\mathrm{I}}$. No further assumptions or parameter fitting were used for the calculation of $P^{\text {th }}$. 
Table 1

Parameter configurations $\left(n_{\mathrm{S}} ; q ; p\right)$ investigated in the calibration experiments

\begin{tabular}{rll}
\hline$n_{\mathrm{S}}$ & $q(\mathrm{Lpm})$ & $p(\mathrm{hPa})$ \\
\hline 3 & 0.99 & $200,400,600,800,950$ \\
8 & $0.99,1.51,1.61,1.89$ & 955 \\
10 & 1.51 & $200,400,600,800,950$ \\
17 & 1.46 & $200,400,600,800,950$ \\
17 & 0.99 & 955 \\
\hline
\end{tabular}

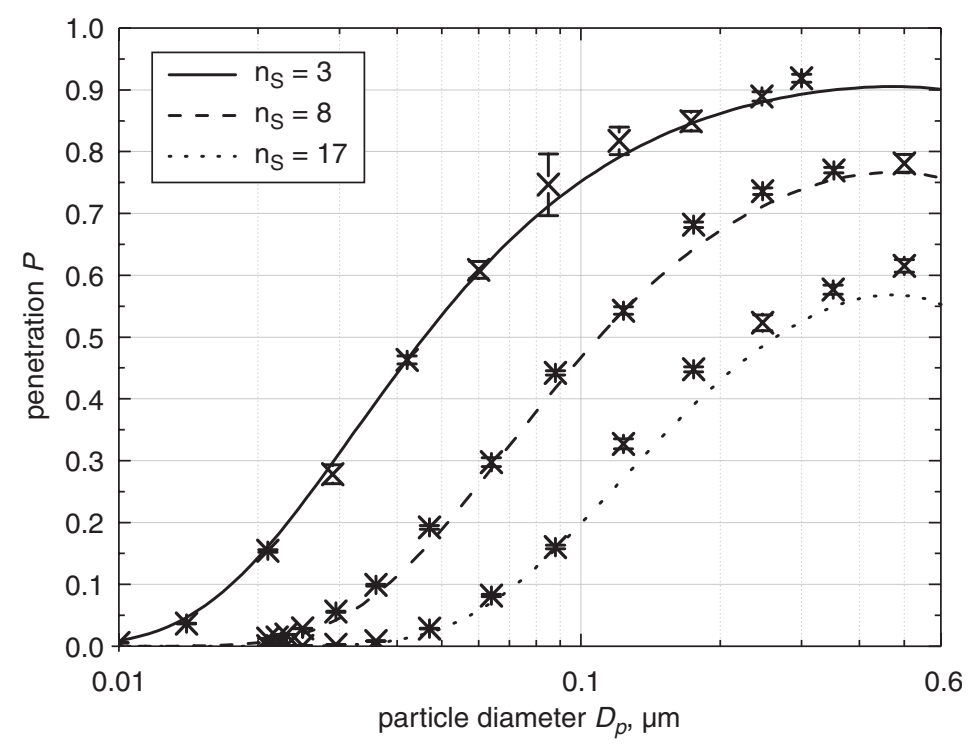

Fig. 4. Comparison between theory (lines) and experiment (data points with error bars): $P\left(D_{\mathrm{p}}\right)$ as a function of $n_{\mathrm{S}}$ for parameter combinations $\left(n_{\mathrm{S}}=3 ; q=0.99 \mathrm{Lpm} ; p=950 \mathrm{hPa}\right),\left(n_{\mathrm{S}}=8 ; q=0.99 \mathrm{Lpm} ; p=955 \mathrm{hPa}\right)$, and $\left(n_{\mathrm{S}}=17 ; q=0.99 \mathrm{Lpm} ; p=950 \mathrm{hPa}\right)$.

Fig. 4 illustrates the dependence of penetration $P$ on the number of screens for values $n_{\mathrm{S}}=3,8$, and 17 with constant parameters $(q=0.99 \mathrm{Lpm}, p=950 \mathrm{hPa})$. The theoretical curves $P^{\text {th }}$ are well reproduced by the experimental data $P^{\mathrm{ex}}$, with the agreement being closest for small particle sizes where the mechanism of diffusion is dominant. For particle sizes close to the theoretically predicted penetration maximum, the difference between theory and experiment increases with increasing number of screens. Since in Eq. (2) the independence of the active particle deposition processes is assumed, the total single-fibre efficiency $E_{\Sigma}$ may be overestimated particularly in those cases where several deposition mechanisms contribute significantly to the total single-fibre efficiency. In turn, $P^{\text {th }}$ may be underestimated at its maximum value, see Fig. 1. However, the relative error $1-\left|P^{\mathrm{ex}} / P^{\text {th }}\right|$ even for large particles of $D_{\mathrm{p}} \cong 100 \mathrm{~nm}$ is only of the order of $10 \%$.

The effect of the volumetric flow rate $q$ through the DS on the total penetration $P$ is illustrated in Fig. 5, which shows $P^{\mathrm{ex}}$ and $P^{\text {th }}$ for the parameter configurations $\left(n_{\mathrm{S}}=8, p=955 \mathrm{hPa}\right)$ and $q=0.99,1.51$, 1.61 and $1.89 \mathrm{Lpm}$. With increasing flow rate $q$, the flow velocity $U_{0}$ through the screens increases. This 


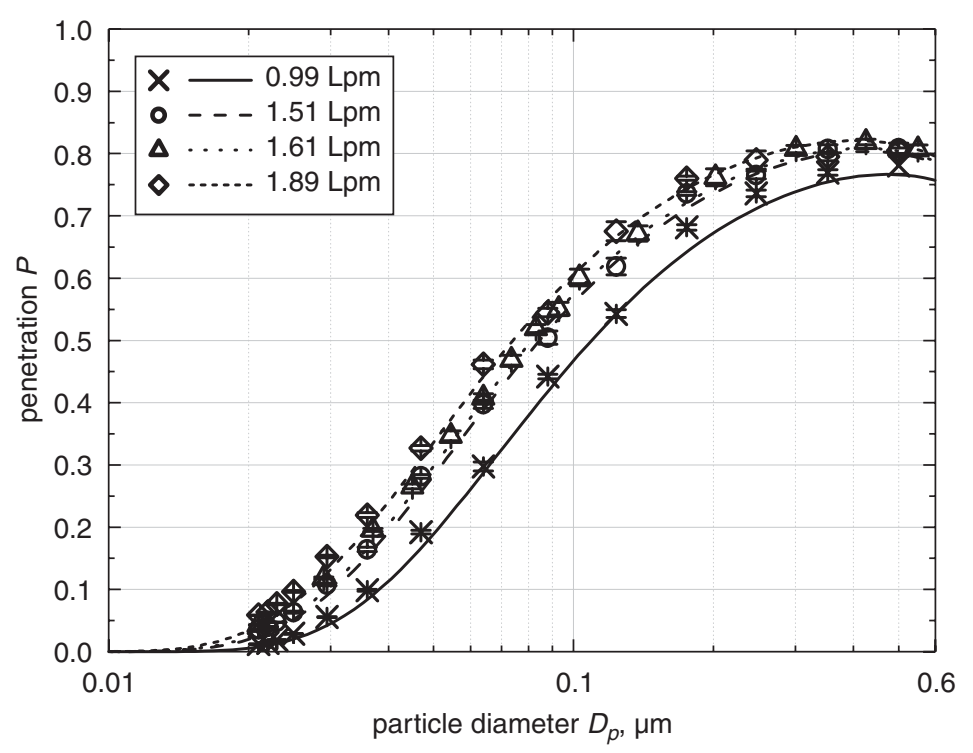

Fig. 5. Comparison between theory (lines) and experiment (data points with error bars): $P\left(D_{\mathrm{p}}\right)$ as a function of $q$ for parameter combinations $n_{\mathrm{S}}=8, p=955 \mathrm{hPa}, q=0.99,1.51,1.61,1.89 \mathrm{Lpm}$.

effect influences the single-fibre efficiencies $E_{\mathrm{I}}, E_{\mathrm{D}}$, and $E_{\mathrm{DR}}$. The comparison between $P^{\mathrm{ex}}$ and $P^{\text {th }}$ shows excellent agreement without any significant trend of deviations. In general terms, the effect of the volumetric flow rate on the penetration efficiency is weak compared to the effect of the number of screens.

The pressure dependence of penetration $P$ impacts mainly the particle diffusion deposition $E_{\mathrm{D}}$ and less distinctly the interaction term $E_{\mathrm{DR}}$. Fig. 6 shows the investigated parameter configuration $n_{\mathrm{S}}=$ $3, q=0.99 \mathrm{Lpm}$ ) and pressure levels $p=200,400,600,800$, and $950 \mathrm{hPa}$. The parameter configurations $\left(n_{\mathrm{S}}=10, q=1.51 \mathrm{Lpm}\right)$ and $\left(n_{\mathrm{S}}=17, q=1.46 \mathrm{Lpm}\right)$ were investigated at the same pressure levels as the $n_{\mathrm{S}}=3$ case. The relative error of the penetration function for particles with $D_{\mathrm{p}} \geqslant 40 \mathrm{~nm}$ is less than $5 \%$ for all investigated parameter configurations.

One remaining open question is the appropriateness of the value of 2.70 for the empirical factor $B$ in Eq. (5), because the factor $B$ appearing in $E_{D}$ was originally evaluated only for standard pressure conditions by Kirsch and Fuchs (1968). In order to evaluate $B$ for all investigated parameter combinations, Eqs. (2) and (5) are inserted into Eq. (1) which leads to

$$
P=\exp \left(-\frac{4 \alpha t}{\pi(1-\alpha) D_{\mathrm{f}}}\left[E_{\mathrm{R}}+E_{\mathrm{I}}+E_{\mathrm{DR}}+B P e^{-2 / 3}\right]\right) .
$$

Particle deposition by gravitational settling and electrostatic forces according to $E_{\mathrm{G}}$ and $E_{\mathrm{q}}$ are neglected. By defining $S=4 \alpha t /\left(\pi(1-\alpha) D_{\mathrm{f}}\right)$ Eq. (7) is expressed as

$$
-\ln P-S\left[E_{\mathrm{R}}+E_{\mathrm{I}}+E_{\mathrm{DR}}\right]=S B P e^{-2 / 3} .
$$

The value of $B$ is determined from Eq. (8) via linear regression analysis by plotting ( $-\ln P-S\left[E_{\mathrm{R}}+E_{\mathrm{I}}+\right.$ $\left.\left.E_{\mathrm{DR}}\right]\right) / S$ as a function of $P e^{-2 / 3}$. This method was applied to the experimental penetration function values. Penetration values $P\left(D_{\mathrm{p}}\right)$ for particle sizes $D_{\mathrm{p}} \leqslant 25 \mathrm{~nm}$ were neglected because the 


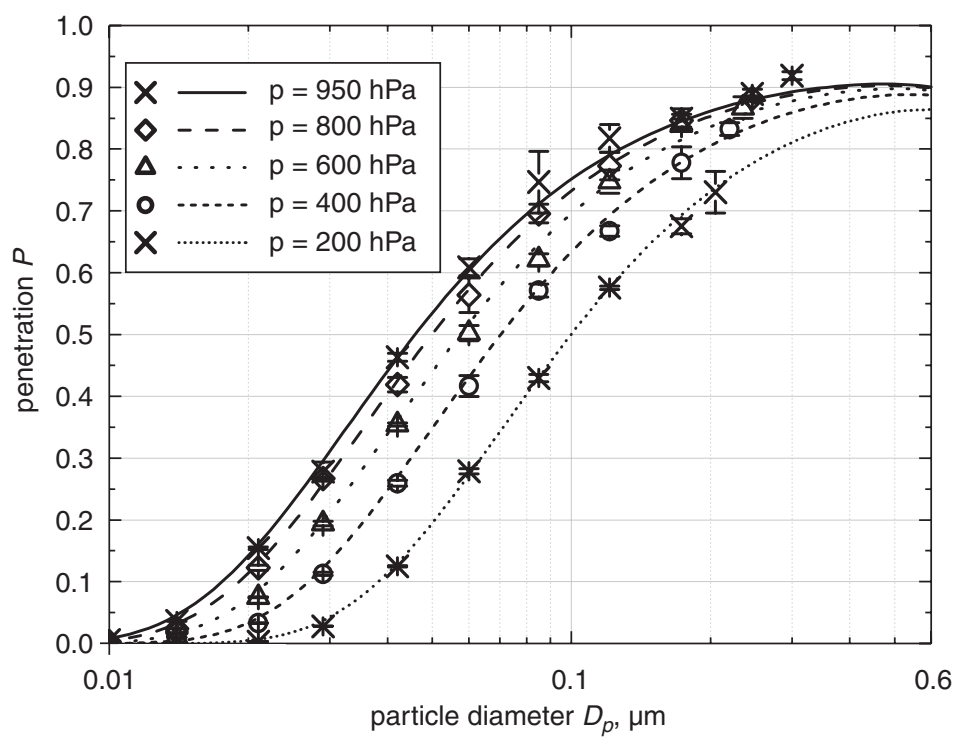

Fig. 6. Comparison between theory (lines) and experiment (data points with error bars): $P\left(D_{\mathrm{p}}\right)$ as a function of $p$ for parameter combinations $n_{\mathrm{S}}=3, q=0.99 \mathrm{Lpm}, p=200,400,600,800,950 \mathrm{hPa}$.

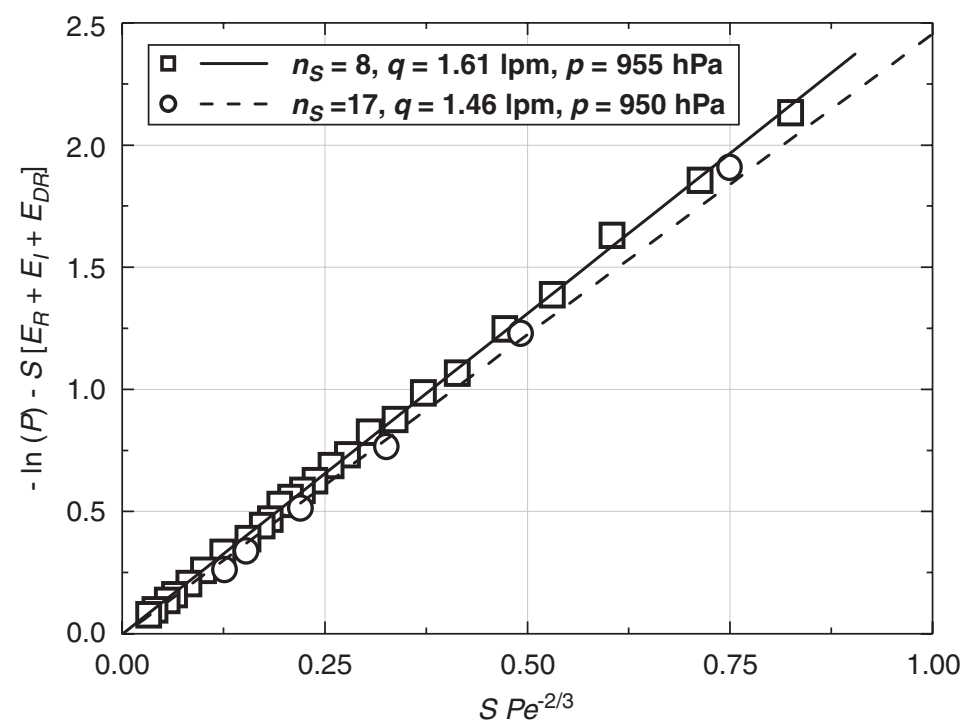

Fig. 7. Examples of the method used to determine $B$ by linear regression; values originate from experiments (data points) and solid lines refer to linear regression (lines).

relative errors in $P$ increase with decreasing $D_{\mathrm{p}}$. Fig. 7 shows two examples of the linear regression lines while Table 2 summarises the results of all conducted linear regression analyses. All correlation coefficients found indicate a statistical significance level $\geqslant 99 \%$ (Doerffel, 1990). Since for all $y$-axis intercept 
Table 2

Results of calculating $B$ by linear regression analysis: $y$-axis intercept $A \pm \Delta A$; slope $B \pm \Delta B$; coefficient of correlation $r$; number of data pairs $n$

\begin{tabular}{|c|c|c|c|c|c|c|c|c|c|}
\hline \# & $n_{\mathrm{S}}$ & $q(\mathrm{Lpm})$ & $p(\mathrm{hPa})$ & $A$ & $\Delta A$ & $B$ & $\Delta B$ & $r$ & $n$ \\
\hline 1 & 3 & 0.99 & 200 & -0.091 & 0.043 & 3.168 & 0.051 & 0.9992 & 8 \\
\hline 2 & 3 & 0.99 & 400 & -0.054 & 0.027 & 3.086 & 0.033 & 0.9996 & 9 \\
\hline 3 & 3 & 0.99 & 600 & -0.017 & 0.015 & 2.934 & 0.037 & 0.9995 & 8 \\
\hline 4 & 3 & 0.99 & 800 & -0.039 & 0.018 & 2.970 & 0.035 & 0.9995 & 9 \\
\hline 5 & 3 & 0.99 & 950 & -0.044 & 0.012 & 2.981 & 0.027 & 0.9997 & 10 \\
\hline 6 & 8 & 0.99 & 955 & 0.000 & 0.015 & 2.606 & 0.020 & 0.9997 & 12 \\
\hline 7 & 8 & 1.51 & 955 & 0.005 & 0.015 & 2.647 & 0.025 & 0.9995 & 12 \\
\hline 8 & 8 & 1.61 & 955 & -0.002 & 0.006 & 2.624 & 0.016 & 0.9996 & 25 \\
\hline 9 & 8 & 1.89 & 955 & 0.017 & 0.010 & 2.570 & 0.023 & 0.9996 & 11 \\
\hline 10 & 10 & 1.51 & 200 & 0.228 & 0.089 & 2.630 & 0.043 & 0.9992 & 8 \\
\hline 11 & 10 & 1.51 & 400 & 0.051 & 0.029 & 2.818 & 0.022 & 0.9998 & 8 \\
\hline 12 & 10 & 1.51 & 600 & 0.005 & 0.024 & 2.817 & 0.024 & 0.9998 & 8 \\
\hline 13 & 10 & 1.51 & 800 & 0.021 & 0.023 & 2.733 & 0.018 & 0.9999 & 9 \\
\hline 14 & 10 & 1.51 & 950 & -0.015 & 0.022 & 2.766 & 0.020 & 0.9998 & 10 \\
\hline 15 & 17 & 1.46 & 200 & 0.306 & 0.089 & 2.372 & 0.054 & 0.9990 & 6 \\
\hline 16 & 17 & 1.46 & 400 & 0.107 & 0.077 & 2.498 & 0.049 & 0.9990 & 7 \\
\hline 17 & 17 & 1.46 & 600 & 0.083 & 0.065 & 2.435 & 0.037 & 0.9993 & 8 \\
\hline 18 & 17 & 1.46 & 800 & 0.058 & 0.054 & 2.426 & 0.037 & 0.9993 & 8 \\
\hline 19 & 17 & 1.46 & 950 & -0.007 & 0.037 & 2.461 & 0.030 & 0.9995 & 9 \\
\hline 20 & 17 & 0.99 & 955 & 0.010 & 0.061 & 2.515 & 0.044 & 0.9986 & 11 \\
\hline
\end{tabular}

values $A \leqslant 3 \times \Delta A$, the intercepts are statistically insignificant and the linear regression lines intercept the $y$-axis at its origin. Thus, $S\left[E_{\mathrm{R}}+E_{\mathrm{I}}+E_{\mathrm{DR}}\right]$ represents the active deposition processes adequately and the negligence of the terms $E_{\mathrm{G}}$ and $E_{\mathrm{q}}$ in Eqs. (2) and (8) is justified.

In Fig. 8, all determined values $B \pm \Delta B$ of the linear regression analyses are compiled. Starting from the top panel of Fig. 8, there is no distinct trend of the influence of the volumetric flow rate $q$ on $B\left(q, n_{\mathrm{S}}=8, p=955 \mathrm{hPa}\right)$ observed. The mid-panel shows the effect of the operation pressure level on $B(p)$ for the parameter configurations $\left(n_{\mathrm{S}}=3 ; q=0.99 \mathrm{Lpm}\right),\left(n_{\mathrm{S}}=10 ; q=1.51 \mathrm{Lpm}\right)$, and $\left(n_{\mathrm{S}}=17 ; q=1.46 \mathrm{Lpm}\right)$ with $p$ varying between 200 and $955 \mathrm{hPa}$. Again, for a fixed number of screens there is no distinct trend observed. However, $B$ values differ significantly for different values of $n_{\mathrm{S}}$, since the three sets of data points in $B(q)$ for the respective $n_{\mathrm{S}}$ values do not overlap. The median values of $B$ are $B\left(n_{\mathrm{S}}=3\right)=2.95, B\left(n_{\mathrm{S}}=10\right)=2.82$, and $B\left(n_{\mathrm{S}}=17\right)=2.43$. Thus, $B$ decreases with increasing $n_{\mathrm{S}}$. This dependence is more clearly illustrated in the bottom panel of Fig. 8.

The variability of the factor $B$ was obtained from a statistical analysis of all determined $B$ values with the results shown in Table 3. For illustrating the effect of the variation in $B$ on the penetration $P$, the penetration curves for three examples were calculated with $B$ being set to $B \pm \Delta B=2.70 \pm 0.23$. The resulting penetration curves are plotted in Fig. 9. The straight lines represent the penetration curves for $B=2.70$. The corresponding grey shaded area indicates respective penetration curves for $(B-\Delta B) \leqslant B \leqslant(B+\Delta B)$. Most of the experimentally determined penetration values fall within the area of uncertainty in $P$. It is thus concluded, that even neglecting the weak effect of $n_{\mathrm{S}}$ on $B$ and setting $B=2.70$ for all investigated operation parameter values, would cause an acceptable uncertainty in the penetration function $P$. However, 

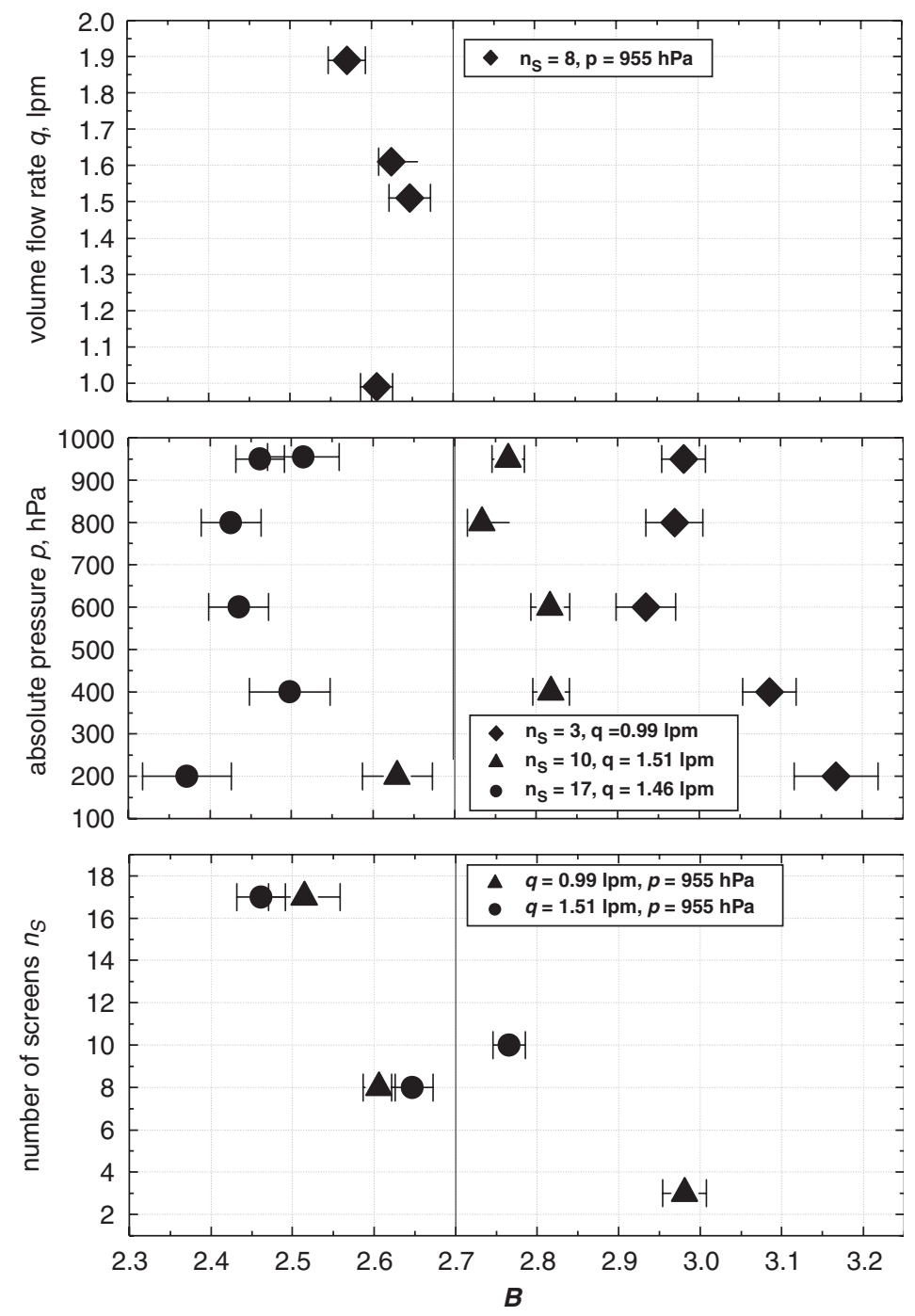

Fig. 8. Calculated $B$ values ( $B \pm \Delta B$ from linear regression analysis) vs. $q, p$, and $n_{\mathrm{S}}$.

values of $B$ for fixed DS configurations as a function of the number of screens will be used in the data analysis of parallel-operated CPC-DS combinations.

Summarising, the obtained results for particle penetration through diffusion screens are within the error limits in excellent agreement with established theory. Considering the effects of varying the number of screens $n_{\mathrm{S}}$, volumetric flow rate $q$, and operation pressure $p$ on the penetration function $P$, the number of screens has the largest effect with respect to the size spectrum of penetrating particles, whereas the volumetric flow rate has only a weak effect. These results, however, are well known and form the basis of any classical screen-type diffusion battery (Cheng \& Yeh, 1980; Hinds, 1999). Of higher importance particularly with respect to a potential application of CPC-DS configurations in airborne 
Table 3

Statistics of determined values of the factor $B$

\begin{tabular}{lc}
\hline Statistical parameter & Value \\
\hline Mean $B$ & 2.703 \\
Standard deviation $\Delta B$ & 0.233 \\
Median $B$ & 2.630 \\
25 percentile & 2.515 \\
75 percentile & 2.818 \\
Number of data & 20 \\
\hline
\end{tabular}

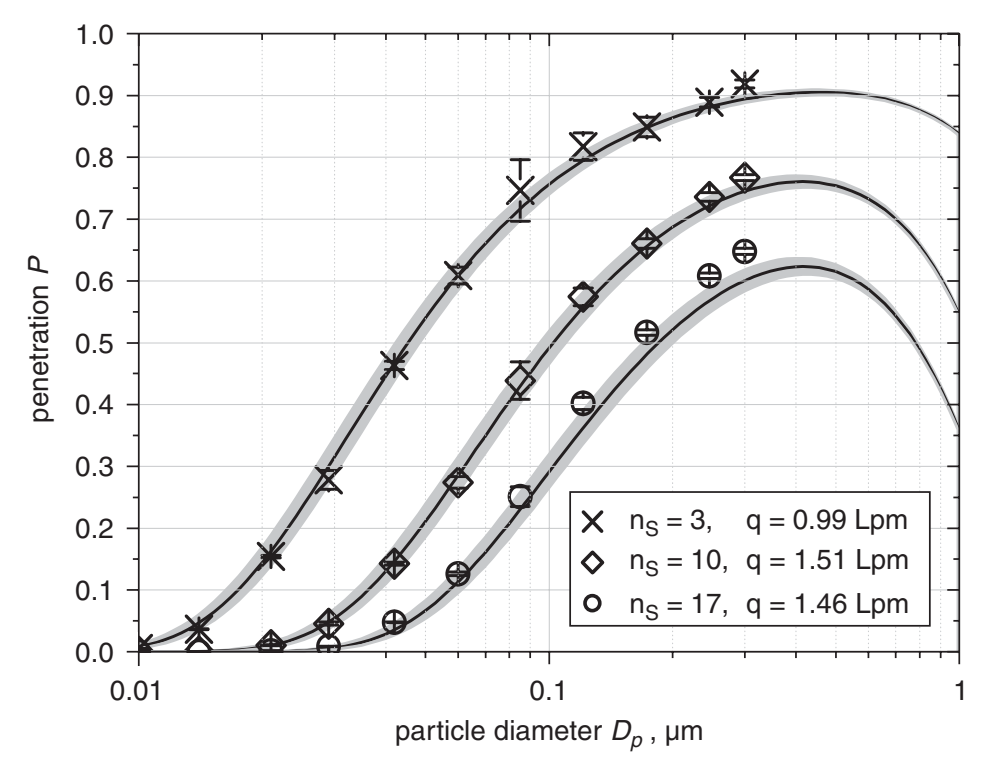

Fig. 9. Penetration curves calculated with $B=2.70 \pm 0.23$ vs. experimental data; the grey shaded areas indicates the uncertainty introduced in $P$ by the uncertainty in $B$.

aerosol measurements at higher altitudes on research aircraft is the effect of reduced pressure on the penetration $P$. Generally, the validity of the penetration theory originally derived for standard pressure conditions is empirically expanded into the pressure range from $955 \mathrm{hPa}$ down to $200 \mathrm{hPa}$. Experiment and theory demonstrate, that for a fixed number of screens, e.g. $n_{\mathrm{S}}=3$ (see Fig. 6), the diameter at $50 \%$ penetration shifts from $45 \mathrm{~nm}$ at $950 \mathrm{hPa}$ to $100 \mathrm{~nm}$ at $200 \mathrm{hPa}$. Since the theory of particle penetration through a screen-type diffusion separator shows excellent agreement for all investigated variations of operation parameters $\left(n_{\mathrm{S}}, q, p\right)$, the penetration curves can be parameterised for the investigated parameter range and used for the inversion of size distribution data measured by CPC-DS combinations. Particularly, the impact of any variability in the operation pressure $p$ on penetration $P$ can be treated by the parameterised penetration function as defined in Eqs. (1)-(5). 
Table 4

Parameter values used for the calculation of the CPC-DS response functions

\begin{tabular}{lclllrll}
\hline DS system & $n_{\mathrm{S}}$ & CPC & $a$ & $b$ & $D_{1}$ & $D_{2}$ & $q(\mathrm{Lpm})$ \\
\hline DS 1 & 3 & mod. TSI 3010 & 0.830 & 0.9383 & 6.025 & 1.3067 & 1.01 \\
DS 2 & 8 & mod. TSI 3760A & 0.854 & 0.9383 & 6.025 & 1.3067 & 1.54 \\
DS 3 & 17 & TSI 3760A & 0.869 & 0.850 & 15.258 & 2.75 & 1.53 \\
& & mod. TSI 3010 & 0.846 & 0.780 & 3.51 & 0.08 & 0.947 \\
\hline
\end{tabular}

a The temperature difference between CPC condenser and saturator was modified according to the approach described by Schröder and Ström (1997).

\section{Validation: Monodisperse experiment}

The verification of the predictability of the response characteristics of any CPC-DS-based instrument was conducted using three CPC combined with different DS separators. Another CPC was used as a reference counter. The entire system was first tested with monodisperse carbonaceous particles, because data interpretation can be performed directly and requires no application of a data inversion algorithm. The set-up for this experiment is quite similar to the set-up of the calibration experiments (see Fig. 3) except that the calibration CPC together with the reference line was replaced by three parallel-operated CPC-DS combinations. Downstream the neutraliser after the DMA the aerosol flow was split into four branches. Three branches were connected to CPC-DS combinations, while the fourth part was led directly into a reference counter. The aerosol was generated by the aerosol generator PALAS GfG 1000. For a fixed particle diameter, the experimental penetration values of the three CPC-DS systems were calculated from the ratios $N\left([\mathrm{CPC}-\mathrm{DS}]_{\#=1 \ldots 3}\right) / N\left(\mathrm{CPC}_{\text {Reference }}\right)$. At pressure $p=951 \mathrm{hPa}$ the particle sizes $D_{\mathrm{p}}=10$, $18,40,100$, and $300 \mathrm{~nm}$ were chosen.

According to Banse, Esfeld, Hermann, Sierau, and Wiedensohler (2001) the transfer function of a CPC can be described by a sigmoidal function

$$
T_{\mathrm{CPC}}\left(D_{\mathrm{p}}\right)= \begin{cases}a-b\left(1+\exp \left(\frac{D_{\mathrm{p}}-D_{1}}{D_{2}}\right)\right)^{-1} ; & D_{\mathrm{p}} \geqslant D_{0}, \\ 0 ; & D_{\mathrm{p}}<D_{0}\end{cases}
$$

with $D_{0}=D_{2} \ln (b / a-1)+D_{1}, a, b, D_{1}$, and $D_{2}$ are fitting parameters. Table 4 compiles the parameters used for the calculation of the CPC response functions. To obtain the total response function $\mathrm{Tr}$ of a CPC-DS combination, the DS penetration function $P$ from Eq. (1) has to be multiplied by the corresponding CPC transfer function $T_{\mathrm{CPC}}$ according to Eq. (9) which then yields

$$
\operatorname{Tr}=P \times T_{\mathrm{CPC}}
$$

In Fig. 10, the experimental results (data points with error bars) and the theoretically predicted response curves of the CPC-DS systems are presented. The monodisperse validation experiment shows excellent agreement between predicted and measured response characteristics for all parameter configurations and calculated error limits. 


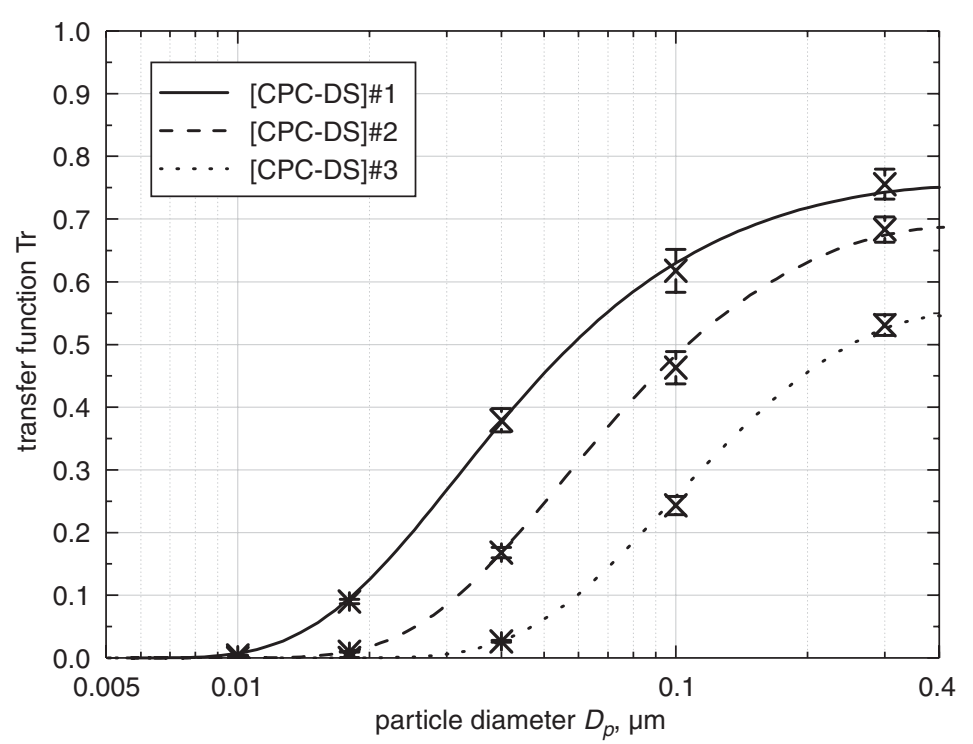

Fig. 10. Validation of the penetration of the three investigated CPC-DC combinations using monodisperse aerosol; lines represent theoretical penetration curves, symbols with error bars refer to experimental data.

\section{Operational test: Polydisperse experiment}

As an operational test, a validation experiment using polydisperse aerosol was implemented. In order to cover both the nucleation- and Aitken-mode size ranges, a three channel CPC-DS system was combined with the four-channel CPSA. A separate DMA also covering the respective size range was used as an independent measurement system to validate the CPSA/CPC-DS results. The CPSA system delivers size information from 4 to $20 \mathrm{~nm}$, while the three-channel CPC-DS system was designed to provide information of the size distribution in the range of about $20-120 \mathrm{~nm}$. The entire system should be able to characterise a polydisperse aerosol from about 4 to $120 \mathrm{~nm}$. In Fig. 11 the transfer functions of all used CPC-DS and CPSA systems are presented. Fig. 12 shows the experimental set-up.

The aerosol was generated by the GfG 1000 generator, using three different settings for the spark discharge frequency. The aerosol was fed through a first DS (DS 4 in Fig. 12) in order to reduce the particle number density for avoiding an overflow of the particle counting rates in the used CPC. The DMA was used in a closed-loop set-up similar to the calibration experiments. The aerosol flow which was probed by the CPC combination was diluted by an isokinetic double stage dilution system (VKL-10, PALAS, Karlsruhe, (Helsper, Mölter, \& Haller, 1990)). The total dilution factor was about $1.4 \times 10^{3}$. In order to minimise the electrostatic attraction term $E_{\mathrm{q}}$, the diluted probe aerosol was brought into a charge equilibrium by passing a neutraliser. After neutralisation the aerosol was split and led simultaneously through the three CPC-DS and the four CPSA channels.

The measured data were converted to size distributions by using the size distribution inversion algorithm developed by Fiebig, Stein, Schröder, Feldpausch, and Petzold (2005). The results of the inversions are presented in the Figs. 13-15. The plotted size distributions originate from the DMA and from the CPC-DS and CPSA data, multiplied by the dilution factor. The size distribution shown in Figs. 13-15 were also 


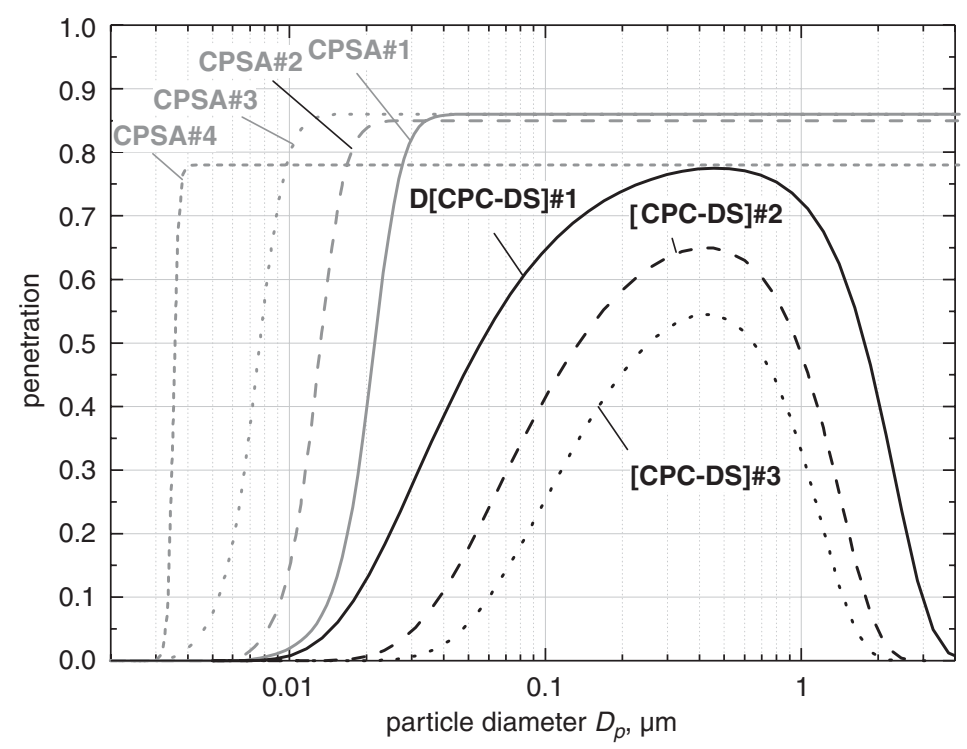

Fig. 11. Transfer functions of used CPC-DC combinations and CPSA systems.

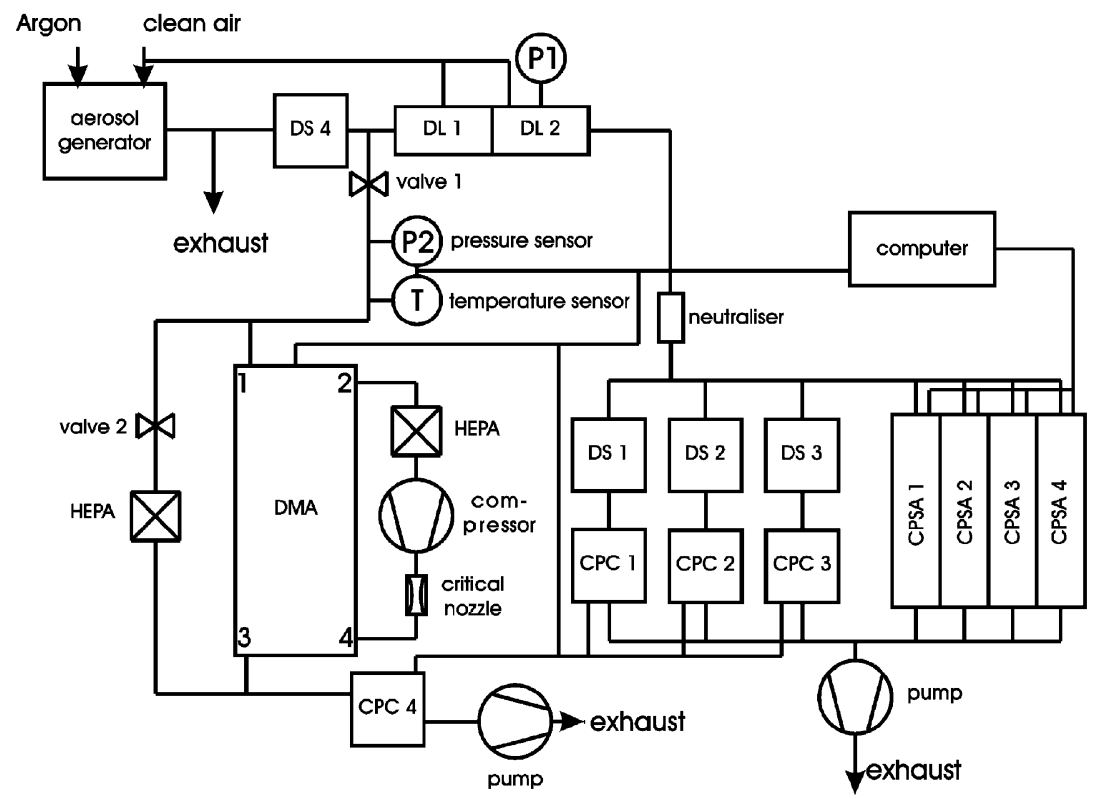

Fig. 12. Experimental set-up for testing the CPC-DC system in combination with the CPSA under operational conditions.

used in Fiebig et al. (2005) as test cases for the new size distribution inversion algorithm. Therefore, these figures are also shown in the paper by Fiebig et al. (2005) in the Journal of Aerosol Science. The error in the DMA-derived size distributions is indicated by the thin solid lines enveloping the dashed-lined 


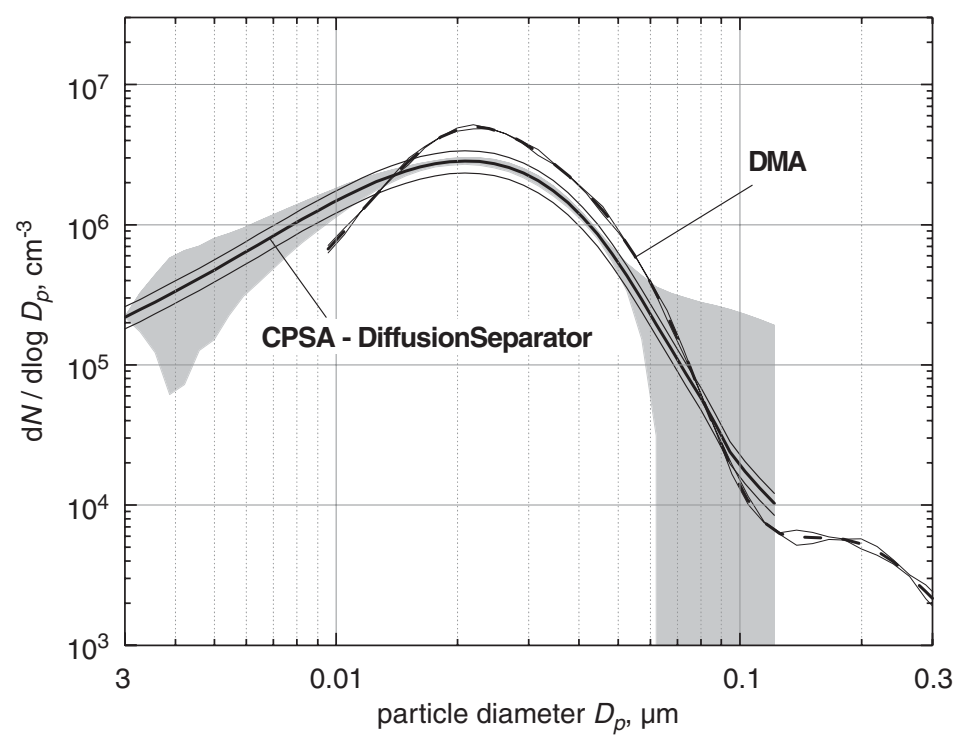

Fig. 13. Particle size distributions, measured by a DMA and determined with the DS-CPC and CPSA systems, aerosol generator setting 1 (Fiebig et al., 2005).

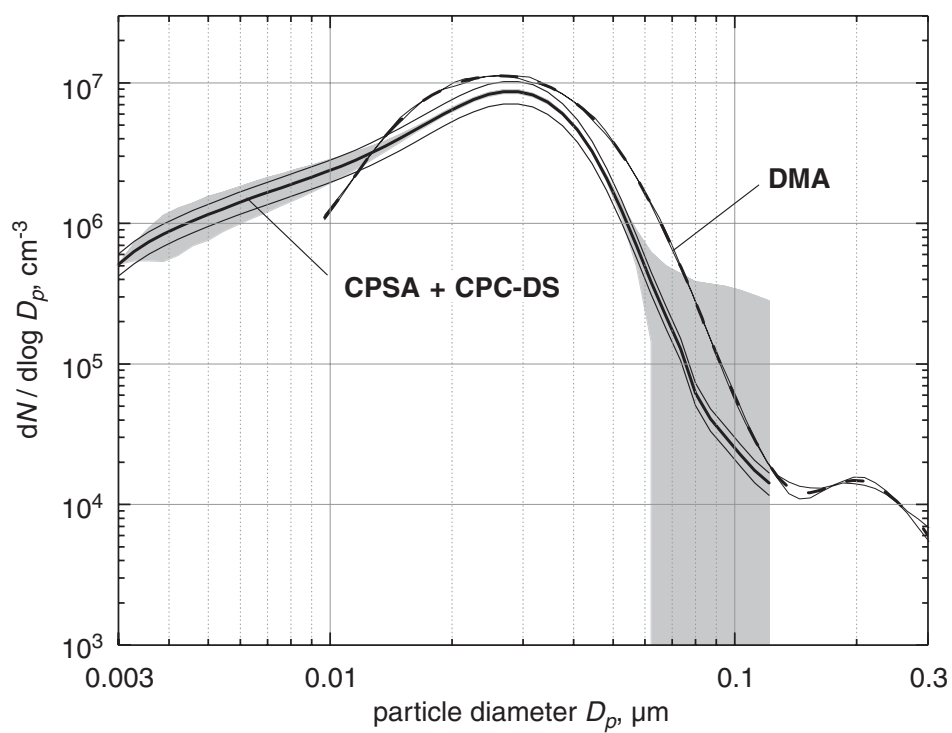

Fig. 14. Particle size distributions, measured by a DMA and determined with the DS-CPC and CPSA systems, aerosol generator setting 2 (Fiebig et al., 2005).

size distribution. The errors in the CPSA/CPC-DS size distributions are shown as grey-shaded areas. Compared to the DMA uncertainty the error for the CPC-based size distribution is very large, especially at small-size and large-size limits of the measured particle size range where the size information provided 


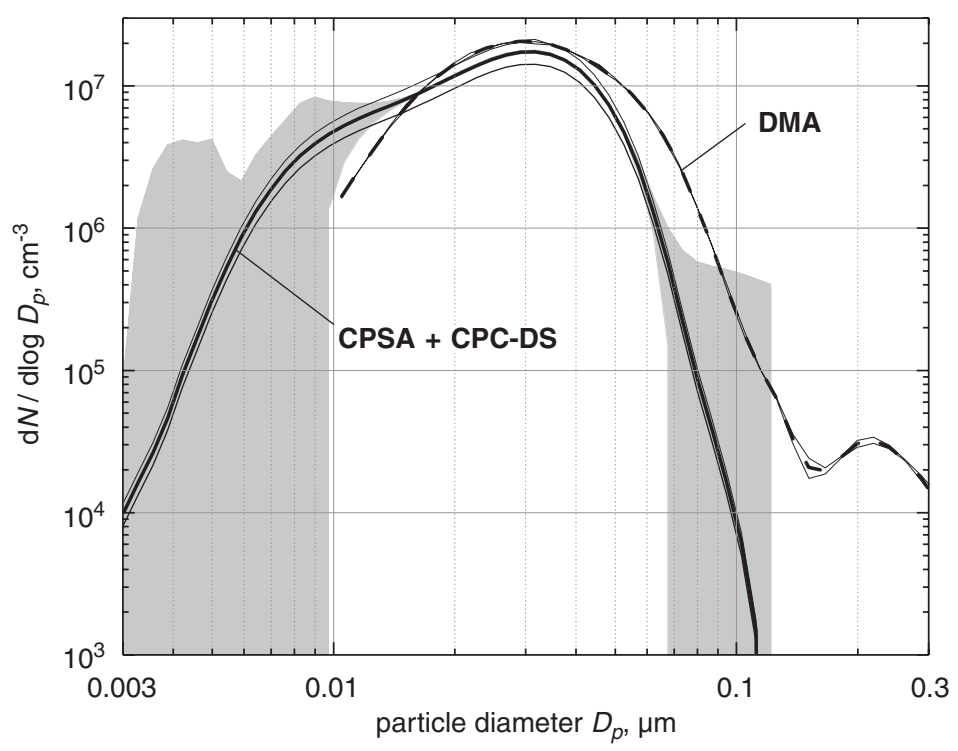

Fig. 15. Particle size distributions, measured by a DMA and determined with the DS-CPC and CPSA systems, aerosol generator setting 3 (Fiebig et al., 2005).

Table 5

Evaluation results

\begin{tabular}{|c|c|c|c|c|c|}
\hline & \multicolumn{5}{|c|}{ GfG 1000 spark discharge frequency setting } \\
\hline & $D>10 \mathrm{~nm}$ & Dilution & $20 \mathrm{~Hz}$ & $70 \mathrm{~Hz}$ & $140 \mathrm{~Hz}$ \\
\hline \multirow[t]{3}{*}{ DMA } & $N\left(\mathrm{~cm}^{-3}\right)$ & & 2152000 & 5447000 & 10200000 \\
\hline & $\mathrm{CMD}(\mu \mathrm{m})$ & & 0.023 & 0.026 & 0.030 \\
\hline & GSD & & 1.510 & 1.529 & 1550 \\
\hline \multirow[t]{3}{*}{ CPSA/CPC-DS } & $N\left(\mathrm{~cm}^{-3}\right)$ & 1400 & 1536000 & 3965000 & 8467000 \\
\hline & $\mathrm{CMD}(\mu \mathrm{m})$ & & 0.025 & 0.027 & 0.028 \\
\hline & GSD & & 1.557 & 1.502 & 1.532 \\
\hline$N, D_{\mathrm{p} 50}=13 \mathrm{~nm}$ & $N\left(\mathrm{~cm}^{-3}\right)$ & 1400 & 1594000 & 4244000 & 8773000 \\
\hline$N, D_{\mathrm{p} 50}=7 \mathrm{~nm}$ & $N\left(\mathrm{~cm}^{-3}\right)$ & 1400 & 1636000 & 4333000 & 8924000 \\
\hline$N_{\mathrm{DMA}} / N_{D>7 \mathrm{~nm}}$ & & & 1.32 & 1.26 & 1.14 \\
\hline$N_{\mathrm{CPC}-\mathrm{DS}} / N_{D>7 \mathrm{~nm}}$ & & & 0.94 & 0.92 & 0.95 \\
\hline
\end{tabular}

by the instruments is poor. The thin lines below and above the CPSA/DS-CPC distributions represent the errors of dilution of about \pm 250 .

The DMA-derived size distributions were regarded as "true" and the CPSA/DS-CPC size distributions were compared to them. Since the particle size sensitivities of the two used instrumentation systems overlap only in the diameter range between 10 and $120 \mathrm{~nm}$, the calculated size distributions were comparable only for these sizes. In Table 5, mode parameters number concentration $N$, count median diameter CMD, and geometric standard deviation GSD of the obtained size distributions are compared. Additionally, 
the total number concentration data are given for the two CPC channels of the CPSA with the closest agreement in their $D_{\mathrm{p} 50}$ values to the size range covered by the DMA and the CPSA/CPC-DS system.

For the investigated input aerosol size distributions, the Aitken mode was detected in a similar diameter range by the applied methods, although details of the size distributions differ significantly. Comparing the CPC-DS and CPSA size distributions to the DMA data, the shapes of the curves and the modal diameters show good agreement. For the GfG spark discharge frequency settings 1 and 2, the input aerosol consists predominantly of sub-50 nm particles, see Figs. 13 and 14. In these cases, the mode parameters N, CMD and GSD agree even quantitatively. By changing the aerosol generator setting to a higher spark ignition frequency a shift of the Aitken mode maximum to a higher number density and higher particle diameters of the DMA size distribution is observable. This shift occurs also in the CPC-DS and CPSA size distributions, as is shown in Fig. 15. Along with the increasing contribution of particles of $D_{\mathrm{p}}>50 \mathrm{~nm}$, the differences in the determined mode parameters increase. Particularly, particles larger than $80 \mathrm{~nm}$ in diameter are considerably underestimated by the CPSA/CPC-DS instrument. This effect results in a narrower size distribution compared to DMA data. Despite this deviation in size distributions at larger particle diameters, the discussed method reproduces the modal diameters of the input size distributions with remarkable agreement Furthermore, the CPSA/CPC-DS based total number concentration data deviate by less than $10 \%$ from the reference data obtained from a single CPC, while the DMA-based data deviate by $14-30 \%$, see Table 5 . However, the real-time capability of the method is achieved at the expense of the detailed size distribution information. Since real-time capability was the desired key feature of this instrument configuration, the presented method is considered a successful measurement technology development and evaluation.

\section{Summary and conclusion}

An instrument set-up for the real-time measurement of ultrafine aerosol size distributions was developed, characterised, and evaluated. The instrument consists of a diffusion screen separator (DS) which is connected to a condensation particle counter (CPC). The DS itself is composed of a number of fine stainless-steel meshes which are placed face-to-face in a gas-tight filter holder. The operation principle of the DS is similar to a screen-type single-stage diffusion battery.

The CPC-DS system was calibrated with monodisperse carbonaceous aerosol particles. The key characteristic property $P$ which describes the penetration of particles through the DS was investigated by varying the operation parameters $n_{\mathrm{S}}$ (number of screens in the DS), $q$ (volumetric flow rate), and $p$ (absolute pressure) within the value ranges $3 \leqslant n_{\mathrm{S}} 17,0.99 \leqslant q \leqslant 1.89 \mathrm{Lpm}$, and $200 \leqslant p \leqslant 955 \mathrm{hPa}$. Theoretical penetration curves as a function of particle size were obtained from the single-fibre deposition efficiencies reported by Hinds (1999). The comparison between calibration experiment and the established theory shows excellent agreement within the calculated error limits. Based on the calibration experiments which were also performed under low-pressure conditions, the applicability of the theory of diffusion deposition was extended from standard conditions down to pressure levels of $200 \mathrm{hPa}$. Particularly, the empirical factor $B$ which controls the single-fibre efficiency $E_{\mathrm{D}}$ for diffusion deposition was shown to be $2.70 \pm 0.23$ over the entire investigated pressure range. The calibration results were successfully validated by a three channel DS-CPC combination using monodisperse aerosol particles. Since the applied DS is comparable to the commercially available Particle Size Selector Model 376060 of TSI Inc., the reported results for the penetration efficiencies are transferable to the application of TSI Model 376060. 
The calibration experiments were performed with a single type of test aerosol. In Eqs. (1)-(5) spherical particle shape is assumed. Except for the single-fibre efficiency of impaction deposition where the particle mass density is needed for determining the Stokes number, no further particle-specific data enter the respective equations. Since even for the nonspherical carbonaceous spark-discharge aerosol a close agreement between experimental and theoretical penetration values was achieved, no severe deviations from the obtained results are expected for other aerosol materials. Nevertheless, DS characterisation studies with further particular matter will be part of future research work. Concerning the type of particle diameter measured by the presented method, the entire calibration work is based on monodisperse particles selected by a DMA. Although, the deposition process occurring in the DS is related to the deposition diameter, the calibration itself builds on the mobility diameter. Since for data inversion purposes the validated penetration functions are used, the particle size measured by the proposed technique is interpreted as being quasi-equivalent to the mobility diameter.

The developed three-channel CPC-DS system was combined with an existing four-channel condensation particle size analyser (CPSA) which is also based on CPC technique. This instrumentation combination was evaluated by characterising a polydisperse aerosol in comparison with a simultaneously operated DMA system. The inverted size distribution data show good agreement within the calculated error limits. Since the used CPC and CPSA modules record their measurement data with a time resolution of $1 \mathrm{~s}$, size distributions can be obtained for averaging periods of 3-5 s, depending on the particle number density in the sampled air. Different to a DMA, the CPC-DS system measures particles independent of their electrical charge. It can thus be applied to the real-time measurement of electrically neutral particles in the sub-100 $\mathrm{nm}$ size range.

The developed, tested, and characterised CPC-DS instrument is expected to be a robust and powerful tool for measuring the ultrafine aerosol fraction from 20 to $150 \mathrm{~nm}$ with a high time resolution in the order of seconds. Concluded from the calibration experiments performed under low-pressure conditions and the high time resolution, the system can be applied on airborne measurements of the aerosol size distribution in the upper troposphere.

\section{References}

Banse, D. F., Esfeld, K., Hermann, M., Sierau, B., \& Wiedensohler, A. (2001). Particle counting efficiency of the TSI CPC 3762 for different operating parameters. Journal of Aerosol Science, 32, 157-161.

Brock, C. A., Schröder, F., Kärcher, B., Petzold, A., Busen, R., \& Fiebig, M. (2000). Ultrafine particle size distributions measured in aircraft exhaust plumes. Journal of Geophysical Research, 105, 26,555-26,567.

Bukowiecki, N., Kittelson, D. B., Watts, W. F., Burtscher, H., Weingartner, E., \& Baltensperger, U. (2002). Real-time characterisation of ultrafine and accumulation mode particles in ambient combustion aerosols. Journal of Aerosol Science, 33, 1139-1154.

Cheng, Y. S., \& Yeh, H. C. (1980). Theory of a screen-type diffusion battery. Journal of Aerosol Science, 11, 313-319.

Doerffel, K. (1990). Statistik in der analytischen chemie. Leipzig: Deutscher Verlag für Grundstoffindustrie GmbH.

Fiebig, M., Stein, C., Schröder, F., Feldpausch, Ph., \& Petzold, A. (2005). Inversion of data containing information on the aerosol particle size distribution using multiple instruments. Journal of Aerosol Science, 36, in press.

Fierz, M., Scherrer, L., \& Burtscher, H. (2002). Real-time measurement of aerosol size distributions with an electrical diffusion battery. Journal of Aerosol Science, 33, 1049-1060.

Flagan, R. C. (2001). Electrical techniques. In P. A. Baron, \& K. Willeke (Eds.) Aerosol measurement (2nd ed.). New York: Wiley, pp. 537-568.

Helsper, C., Mölter, W., \& Haller, P. (1990). Representative dilution of aerosols by a factor of 10000. Journal of Aerosol Science, 21(Suppl. 1), 637-640. 
Helsper, C., Mölter, W., Löffler, F., Wadenpohl, C., \& Kaufmann, S. (1993). Investigations of a new aerosol generator for the production of carbon aggregate particles. Atmospheric Environment, 27A, 1271-1275.

Hinds, W. C. (1999). Aerosol technology. New York: Wiley.

Jokinen, V., \& Mäkelä, J. M. (1997). Closed-loop arrangement with critical orifice for DMA sheath/excess flow system. Journal of Aerosol Science, 28, 643-648.

Kirsch, A. A., \& Fuchs, N. A. (1968). Studies on fibrous aerosol filters-III. Diffusional deposition of aerosols in fibrous filters. Annals of Occupational Hygiene, 11, 299-304.

Knutson, E. O. (1999). History of diffusion batteries in aerosol measurements. Aerosol Science and Technology, 31, 83-128.

Kulmala, M., Vehkamäki, H., Petäjä, T., Dal Maso, M., Lauri, A., Kerminen, V.-M., Birmili, W., \& McMurry, P. H. (2004). Formation and growth rates of ultrafine atmospheric particles: A review of observations. Journal of Aerosol Science, 35, 143-176.

Schröder, F. (2000). Vertikalverteilung und neubildungsprozesse des aerosols und partikelförmige flugzeugemissionen in der freien troposphäre und tropopausenregion. Dissertation, Ludwig-Maximilians-Universität München, DLR Forschungsbericht 2000-35, DLR Köln.

Schröder, F., \& Ström, J. (1997). Aircraft measurements of sub micrometer aerosol particles ( $>7 \mathrm{~nm}$ ) in the midlatitude free troposphere and tropopause region. Atmospheric Research, 44, 333-356.

Stein, C., Schröder, F., \& Petzold, A. (2001). The condensation particle size analyzer: A new instrument for the measurement of ultrafine aerosol size distributions. Journal of Aerosol Science, 32, S381-S382. 